Vol.61: e181605912018

http://dx.doi.org/10.1590/1678-4324-2018160591

ISSN 1678-4324 Online Edition
BRAZILIAN ARCHIVES OF

BIOLOGY AND TECHNOLOGY

AN INTERNATIONAL JOURNAL

\title{
Inulin Induces IL-10 Secretion and Increased FOXP3 Gene Expression in Human Peripheral Blood Mononuclear Cells
}

\author{
Marla Karine Amarante ${ }^{1 *}$, Carolina Batista Ariza ${ }^{1}$, Carlos Eduardo Coral de Oliveira ${ }^{1}$, \\ Karina de Almeida Gualtieri ${ }^{1}$, Julie Massayo Maeda Oda ${ }^{2}$, Maria Angelica Ehara \\ Watanabe ${ }^{1}$. \\ ${ }^{1}$ Universidade Estadual de Londrina, Londrina, Paraná, Brasil; ${ }^{2}$ Universidade Federal do Mato Grosso do Sul, \\ Mato Grosso do Sul, Brasil.
}

\begin{abstract}
Inulin is an effective prebiotic and its potential in modulating systemic immunity have been proposed. A subpopulation of $T$ cells, named $T$ regulatory cells (Tregs), expressing the Forkhead boxP3 transcription factor are key mediators of peripheral tolerance and suppress undesirable immune responses. These Tregs can be induced by cytokine transforming growth factor beta (TGF- $\beta$ ) and interleukin 10 (IL-10). This work aimed to evaluate inulin effects on human peripheral blood mononuclear cells (PBMC) in vitro. PBMC were incubated with inulin, and the expression of TGF- $\beta 1, F O X P 3$ and IL-10 was analyzed. Increased supernatant IL-10 levels were observed in PBMC of inulin-treated group $(p=0.03)$. Moreover, FOXP3 gene expression was 7.6 fold higher in inulin-treated PBMC, whereas a trend in TGF- $\beta 1$ expression was detected $(p=0.055)$. These data suggest that inulin induces an immunosuppressive environment in cultured PBMC by promoting FOXP3 gene expression and IL-10 secretion. These studies offer prospects for further fundamental research in this field.
\end{abstract}

Key words: inulin, FOXP3, TGF- $\beta 1$, IL-10, PBMC.

*Author for correspondence: marla_karine@yahoo.com.br 


\section{INTRODUCTION}

Prebiotics are non-digestible food ingredients that selectively stimulate favorable bacterial growth and/or promote activity of a limited number of health-promoting bacteria, hence benefiting the host $(1,2)$. The vast majority of prebiotic substances are carbohydrates indigestible for human digestive enzymes but can be fermented by beneficial bacterial genera in the colon and serve as a substrate for their metabolism. Examples of prebiotics are fructo-oligosaccharides (FOS), inulin, galactooligosaccharides (GOS), soybean oligosaccharides, and complex polysaccharides that constitute dietary fibers (2).

The $\alpha$-D-glucopyranosyl-[ $\beta$-D-fructofuranosyl](n-1)-D-fructofuranoside, commonly referred to as inulin-type prebiotic compounds are naturally occurring constituents in many plants, containing fructose monomers linked by $\beta 2 \rightarrow 1$ bonds. Root vegetables including Jerusalem artichokes, burdock, chicory, leeks, and onions are especially rich sources (3). Clinical research has led to significant biological activities about inulin-type prebiotics, including effects in infant nutrition, gastrointestinal health, bone mineralization, fatty liver disease, obesity, blood sugar and lipid metabolism, colon cancer prevention $(4,5)$ and immune-modulatory properties $(6,7)$.

Indeed, Bodera (8) reviewed the immunity-enhancing effects of prebiotics and noted that there is compelling evidence demonstrating that prebiotics such as inulin can regulate immunological functions, suggesting that their consumption could modulate immunological parameters in gut-associated lymphoid tissues, secondary lymphoid tissues and peripheral circulation. (9) related that the use of a mixture containing galacto- and fructooligosaccharides in dietary compounds might provide an opportunity to stimulate the adaptive immunological response toward Th1 pattern, inhibiting infections subsequently, and to module Th2 related immunological disorders in humans as, for instance, allergies.

Regulatory T cells (Tregs) are a CD4+ T cell lineage that plays an indispensable role in maintaining immunological unresponsiveness to self-antigens and in suppressing excessive immune responses deleterious to the host. However, they also limit beneficial responses by suppressing sterilizing immunity and limiting antitumour activity (10-12).

The forkhead box protein 3 (FOXP3) is a member of the forkhead winged helix transcription-factor family and is expressed primarily in Tregs, where it plays a critical role in the differentiation, development, maintenance and function of this important subset of cells $(13,14)$. These cells can be generated in the thymus (tTreg cells), or converted from peripheral naive CD4+ T cells to FOXP3+ Treg cells (pTreg cells), through transforming growth factor-beta (TGF- $\beta$ ) induction (15).

The TGF- $\beta$ and interleukin 10 (IL-10) are two immunoregulatory cytokines involved in Treg development and function. It is recognized that TGF- $\beta$ is largely an immunosuppressive cytokine, generally inhibiting immune responses. In addition, TGF- $\beta$ plays a central role in the generation and function of CD4+ CD25+ Tregs (16), but the ultimate effect of TGF- $\beta$ on immune cells is heavily dependent on the microenvironment and the presence of other cytokines and factors, such as IL-10 (17). Further, Murai, Turovskaya (18) demonstrated that myeloid cells act in a paracrine manner secreting IL-10, despite the ability of the donor Treg cells to secrete IL-10, and sustaining FOXP3 expression and their suppressive function.

Although multiple implications for modulation of the immune system via inulin have been suggested, and in vitro studies have demonstrated inulin can bind to certain pattern recognition receptors, it is unclear whether this prebiotic compound might bind to receptors on immune cells to stimulate Treg development in vivo, affecting immunosuppressive balance empowered by these cells. In this context, this work 
investigated the effect of inulin on gene expression of FOXP3 and TGF- $\beta 1$, and Treg-related cytokines release, TGF- $\beta 1$ and IL-10, in human peripheral blood mononuclear cells (PBMC) in vitro.

\section{MATERIAL AND METHODS}

\section{Mononuclear cells from human peripheral blood (PBMC)}

Following approval from the Human Ethics Committee of the State University of Londrina (CAAE 54639716.8.0000.5231), $40 \mathrm{~mL}$ of peripheral blood was obtained from healthy non-smoker volunteers $(n=6,3$ women and 3 men). A term of free informed consent was signed by all sample donors prior to blood collection.

Human PBMCs were separated by Histopaque $\AA-1077$ (Sigma-Aldrich, St Louis, USA) and maintained in RPMI 1640 medium (Gibco, San Francisco, USA) supplemented with $10 \%$ fetal bovine serum (Gibco), $2 \mathrm{mM}$ L-glutamine (Invitrogen, Carlsbad, USA) and penicillin-streptomycin (100 U/ml, Sigma-Aldrich). A total of $1 \times 10^{6} \mathrm{cells} / \mathrm{mL}$ were incubated in the absence or presence of inulin (ORAFTI ${ }^{\circledR} \mathrm{HSI}$ ) at $10 \mathrm{ug} / \mathrm{uL}$ for $24 \mathrm{~h}$ at $37^{\circ} \mathrm{C}$ and $5 \% \mathrm{CO}_{2}$ incubator.

\section{Quantitative determination of lactic dehydrogenase activity}

Cell damage or cell death were determined via measurement of lactate dehydrogenase (LDH) activity (Flex ${ }^{\circledR} \mathrm{LDH}$ reagent cartridge, Atterbury, United Kingdom). Lactate dehydrogenase oxidizes the substrate in the presence of $\mathrm{NAD}^{+}$to yield pyruvate and $\mathrm{NADH}$, which absorbs at $340 \mathrm{~nm}$. The $\mathrm{LDH}$ concentration was determined utilizing Dimension XL® spectrophotometer.

\section{ELISA for determination of TGF- $\beta 1$ and IL-10 in culture supernatants}

Expression of human TGF- $\beta 1$ and IL-10 were performed using ELISA kit BD OptEIA Set Human TGF- $\beta 1$ (BD Biosciences, San Diego, USA) and Human IL-10 ELISA Ready-SET-Go (e-Bioscience Inc, San Diego, U.S.A.). In brief, supernatant from each group was collected after 24 hours culture, added into the precoated plates with anti-human TGF- $\beta 1$ or anti-human IL-10 monoclonal antibodies and incubated overnight at $8{ }^{\circ} \mathrm{C}$. Samples were washed and biotinilated secondary antibodyHRP+Sav conjugated were added. After wash, 3,3',5,5'-tetramethylbenzidine (TMB) peroxidase substrate were immediately added, followed by $1 \mathrm{M}$ Phosphoric acid stop solution. The ELISA plate was read at $450 \mathrm{~nm}$ wavelength using ELX-300 Reader (BioTek Instruments Inc., VT, U.S.A.). The results were expressed in ng/mL for TGF- $\beta 1$ and $\mathrm{pg} / \mathrm{mL}$ for IL-10. Each experimental and control sample was assayed in two biological replicates. Data processing was performed using the analytical curve-fitting software Gen5 (BioTek).

\section{Quantitative real time PCR (qPCR)}

Total RNA from cell cultures were extracted by Trizol LS reagent ${ }^{\circledR}$ (Invitrogen) according to the manufacturer's instructions and quantified using NanoDrop ND2000 Spectrophotometer (NanoDrop Technologies, Wilmington, USA). Total RNA (500 ๆg) were reverse-transcribed with Oligo(dT) Primer (Invitrogen), M-MLV Reverse Transcriptase (Invitrogen), RNaseOUTTM Recombinant Ribonuclease Inhibitor (Invitrogen) and $\mathrm{MgCl}_{2}$. qPCR was performed in triplicates, using Platinum SYBR Green qPCR SuperMix-UDG ${ }^{\circledR}$ (Invitrogen) and StepOne ${ }^{\mathrm{TM}}$ Real-Time PCR Systems (Applied Biosystems, Foster City, USA). The thermal cycling conditions were 10 minutes at $95^{\circ} \mathrm{C}$, and 40 cycles of 15 seconds at $95^{\circ} \mathrm{C}$ and 1 minute at $60{ }^{\circ} \mathrm{C}$, followed by melting curve consisted of one cycle of 15 seconds at $95{ }^{\circ} \mathrm{C}, 1$ minute at $60{ }^{\circ} \mathrm{C}$ and growing increase up to $95^{\circ} \mathrm{C}\left(0.3{ }^{\circ} \mathrm{C} /\right.$ second $)$ with detection of 
fluorescence at each temperature increase to confirm the specific amplification. The primers used were: B2M sense 5'-CACCCCCACTGAAAAAGA- 3'; antisense 5'AAAAAGCAA GCAAGCAGAA-3', FOXP3 sense 5'CACCTGGCTGGGAAAATG G3'; antisense 5'CTGGAGGAGTGCCTGTAAGTG3' and TGF- $\beta 1$ sense 5'GGAGCGGGAGGAG GGAC3'; antisense 5'GAGCCCTTGTCGGATGAT3'. The $2^{-\Delta \mathrm{CT}}$ method was applied to determine the effect of the experimental treatment on the expression of internal control gene $(B 2 M)$; the relative expression levels of genes FOXP3 and $T G F-\beta 1$ were calculated using the $2^{-\Delta \Delta C T}$ method (19).

\section{Statistical analysis}

GraphPad Prism software version 5.01 (GraphPad Software, U.S.A.) was used for all statistical analyses. The distributions of LDH activity and plasma cytokine levels were tested for normality based on the D'Agostino and Pearson omnibus normality test, and non-parametric tests were thus used where appropriate. The MannWhitney's U test was used to compare non-continuous variables. Results are expressed as mean \pm SEM and were considered significant if $p<0.05$.

\section{RESULTS}

\section{Inulin effect in cell viability}

No differences were observed in LDH activity (Figure 1) in cultured PBMC supernatant after 24 hours between untreated $(11.5 \pm 2.777)$ and inulin treated (concentration: $10 \mu \mathrm{g} / \mu \mathrm{L} ; \mathrm{LDH}$ activity: $14.0 \pm 2.619 ; \mathrm{p}=0.125$ ) groups, indicating that, at this concentration, inulin does not present toxicity nor lytic activity in PBMC.

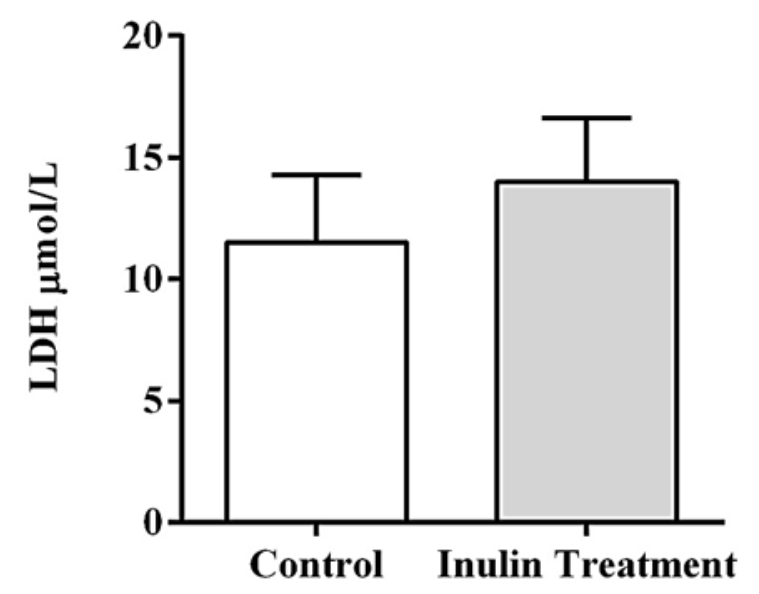

Figure 1-. Evaluation of citotoxic effect of inulin. Quantitative determination of lactic dehydrogenase activity $(\mu \mathrm{mol} / \mathrm{L})$ in supernatant of cultured cells in presence or absence of inulin stimuli. Data presented as mean \pm standard deviation; $\mathrm{t}$ test $\mathrm{p}=0.13$.

\section{Inulin effect in TGF- $\beta 1$ and IL-10 secretion}

Measuring the release of TGF- $\beta 1$ and IL-10 cytokines after inulin treatment of PBMC, we found that production of TGF- $\beta 1$ did not differ between groups (Figure 2a: untreated $721.2 \mathrm{pg} / \mathrm{mL} \pm 244.3$ vs. inulin-treated $1109.0 \mathrm{pg} / \mathrm{mL} \pm 229.2 ; \mathrm{p}=0.32$ ), while the release of IL-10 was significantly increased after 24 hours of culture (Figure 2b: untreated $104.5 \mathrm{pg} / \mathrm{mL} \pm 24.2$ vs. inulin-treated $167.4 \mathrm{pg} / \mathrm{mL} \pm 45.7$; $\mathrm{p}=0.03)$. 
a.

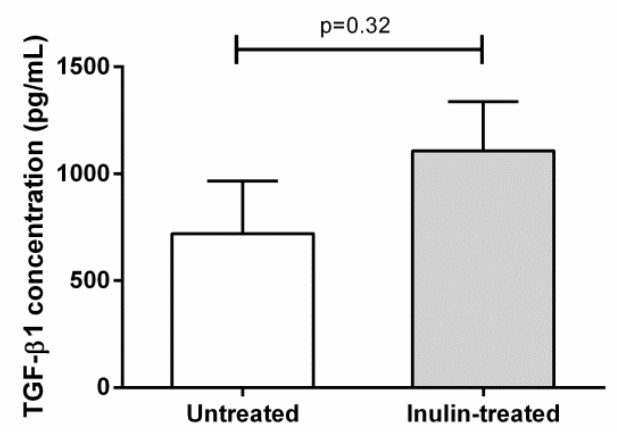

b.

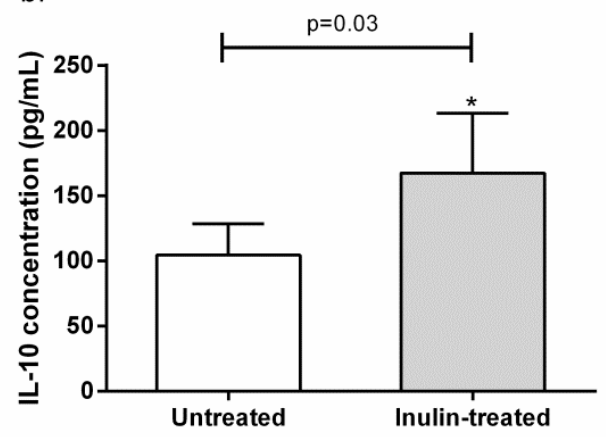

Figure 2-. Increased of IL-10 cytokine but not of TGF- $\beta 1$ upon inulin stimuli on human PBMC cultures. PBMC cells were cultured for 24 hours in 12 wells microplates in the presence of inulin $(10 \mu \mathrm{g} / \mu \mathrm{L})$. The concentration of TGF- $\beta 1$ (panel a) and IL-10 (panel b) cytokines were measured from the supernatants by ELISA kits. Average values \pm SEM obtained in replicated samples are shown. Statistical analysis were evaluated by test using the GraphPad Prism software.

\section{Inulin modulates the expression of $F O X P 3$ and $T G F-\beta 1$ mRNA in human PBMC}

The mRNA from PBMCs, untreated or inulin-treated, was subjected to real-time quantitative PCR using gene-specific primers for $\beta 2$-microglobulin, FOXP3 and $T G F-\beta 1$. The fold change in gene expression was calculated using $2^{-\Delta \Delta \mathrm{CT}}$ method. The results of each gene were normalized to $\beta 2$-microglobulin, which was stable between all samples analyzed.

Different from the ELISA results, qPCR analyses demonstrated a trend toward an up-regulation of TGF- $\beta 1$ in PBMCs inulin-treated compared to untreated cells $(\mathrm{p}=0.055$; figure 3$)$. In relation to the transcription factor FOXP3, inulin treatment was able to increase its expression 7.6 times when compared to untreated cells.

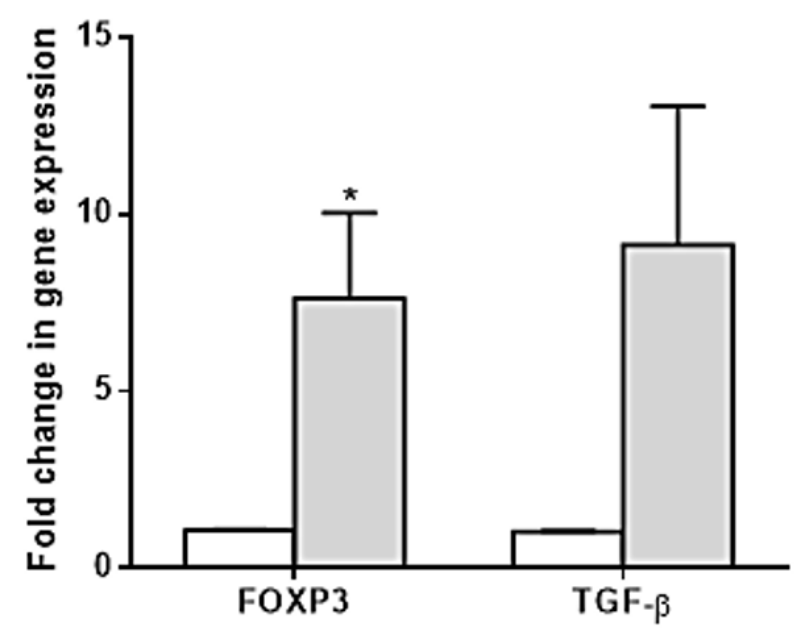

Figure 3-. Induction of FOXP3 expression but not of $T G F-\beta 1$ by inulin-treatment. PBMC cells were incubated for 24 hours in the presence of inulin $(10 \mu \mathrm{g} / \mu \mathrm{L})$. FOXP3 and $T G F-\beta 1$ expression was assessed by qPCR. Relative expression distribution ( $\mathrm{X}$ axis) is represented as fold change (ratio) of PBMC treated (grays bars) versus PBMC untreated (white bars), normalized against $\beta 2$-microglobulin reference gene, * $\mathrm{p}<0.05$ for FOXP3 gene, and $\mathrm{p}=0.055$ for $T G F-\beta 1$. Average values \pm SEM obtained in three independent experiments are shown. 


\section{DISCUSSION}

A major advantage of the use of carbohydrate compounds as immunomodulators is that most carbohydrates are nontoxic and well-tolerated in vivo. In addition, considerable data have been published on the immune action of glucans, including $\beta$ glucan, mannan and lentinan (20).

In order to assess the possible cytotoxicity of inulin on human PBMC, we tested LDH activity measurement. Cell viability determination is crucial for evaluating mutagenesis, malignant transformation, apoptosis, cellular pathology, and pharmaceutical toxicity. Classical apoptosis and necrosis represent only the extreme ends of a wide range of possible morphological and biochemical deaths and can occur simultaneously in tissues and cell cultures exposed to the same stimulus (21). In this work, inulin concentration utilized $(10 \mu \mathrm{g} / \mathrm{uL})$ did not show toxicity nor lytic activity in cultured PBMC, as assessed by LDH assay (Figure 1). In fact, little formal toxicity testing in laboratory animals has been reported on inulin or its oligosaccharide hydrolysis products, and any negative effects have been found for inulin and oligofructose (22).

Beneficial effects of inulin-type fructans were described in studies that applied the oligosaccharides in colon cancer, chronic inflammatory diseases, vaccination efficacy, and prevention of infection and allergy. In addition, it is suggested that immunomodulation is elicited through indirect and direct mechanisms (23).

Recently, the effect of $\beta 2 \rightarrow 1$ fructans with different chain lengths on cytokine release by PBMC was described. Vogt, Ramasamy (24) hypothesized that $\beta 2 \rightarrow 1$ fructans could affect the immune status through physical contact with pattern recognition receptors (PRRs) on gut immune cells such as intra-epithelial lymphocytes or dendritic cells. They demonstrated that $\beta 2 \rightarrow 1$-fructans possess direct signalling capacity on human immune cells, mainly through toll like receptor-2 (TLR2), suggesting that direct TLR2 signaling events on immune cells could be part of the mechanism by which IL-10 production is induced in vivo. They concluded that the short chain molecules which are more abundant in inulin-type fructans I and II, skew the IL-10/IL-12 ratio in PBMCs more towards IL-10, and thus induce a more anti-inflammatory balance, which can partially explain some of the findings from our study where short chain inulin was tested.

The inulin ability to alter expression and release of Treg associated genes and cytokines, respectively, was not investigated so far. In this context, we evaluated the effect of inulin on immunosupressive cytokines TGF- $\beta 1$ and IL-10, and the gene expression of TGF- $\beta 1$ and transcription factor FOXP3 in cultured human PBMC.

Our results demonstrate that inulin does not alter TGF- $\beta 1$ cytokine release after 24 hours, but TGF- $\beta 1$ mRNA was 9.13 fold increased in inulin-treated PBMC cultures, although it was not statistically significant $(p=0.055)$. Increased IL-10 releasing was observed in PBMC of inulin-treated cultures $(\mathrm{p}=0.03)$. Moreover, FOXP3 gene expression was 7.6 fold higher in inulin-treated PBMC cultures. All in all, it is noteworthy that inulin may induce an immunosuppressive environment in cultured PBMC by promoting FOXP3 gene expression and IL-10 secretion. The underlying mechanisms of inulin-induced immunosuppression on human PBMC are likely to be explained by different activating signals.

First, it is well known that some dietary fibers such as $\beta$-glucans modulate the human immune system by binding to PRRs on cells of the innate immune system, such as Dectin-1 and TLR (23-25) They hold the ability to recognize specific carbohydrate moieties, which could be present in $\beta 2 \rightarrow 1$-fructans, and elicit immune responses. In this particular, Vogt, Ramasamy (24) described that activating capacity of $\beta 2 \rightarrow 1$ - 
fructans is MyD88 dependent, and activation of TLR2 is important in the immunomodulatory capacity of $\beta 2 \rightarrow 1$-fructans. In addition, inulin may act as TLR4 ligand or as indirect TLR4 modulator to upregulate TNF- $\alpha$, IL-1 $\beta$, and IL-10 cytokines secretion in human peripheral blood monocytes (25). Thus, the monocyte activation of TLR could induce the production of IL-10 $(18,26)$, which in turn, could maintain FOXP3 expression in Tregs, and might result in polarization of $\mathrm{T}$ CD4 naïve into Treg status (27).

Otherwise, inulin-derivatives are able to activate and exhaust complement when incubated with human serum, and was one of the first substances used for this purpose (7). In a mouse model, Kerekes, Cooper (28) demonstrated that treatment with the gamma-inulin results in deposition of C3-fragments onto the surface of peritoneal macrophages, as does in vitro incubation of the cells with the adjuvant in the presence of fresh autologous serum. Prior incubation of macrophages with gamma-inulin plus serum in vitro enhances subsequent $\mathrm{C} 3$ production. Further, Torok, Dezso (29) reported that engagement of the integral membrane glycoprotein $\mathrm{CR} 1$, that binds to complement ligands $\mathrm{C} 3 \mathrm{~b}$ and $\mathrm{iC} 3 \mathrm{~b}$ as well as $\mathrm{C} 4 \mathrm{~b}$, or by CR1specific antibodies induces the expression of Treg markers, enhances IL-10 production and reduces IFN release by activated CD4+ T cells. It is reasonable to assume that inulin treatment can intermediate CR1 activation, resulting in FOXP3 expression and IL-10 release.

Contrasting results were found by Bermudez-Brito, Sahasrabudhe (30), who verified that the interaction of galacto-oligosaccharides, chicory inulin, wheat arabinoxylan, barley-glucan with human epithelial cells and dendritic cells led to changes in the production of the Th1 cytokines in autologous $\mathrm{T}$ cells, while chicory inulin, and barley-glucan reduced the Th2 cytokine IL-6. The Treg-promoting cytokine IL-10 induced by galacto-oligosaccharides whereas chicory inulin decreased the IL-10 production.

Evidence for direct effects on the immune system generally remains to be confirmed. It is suggested that inulin-type fructans can be detected by gut dendritic cells and these cells may also exert antigen presenting capacity toward effector cells, such as B cells, T cells, and natural killer cells locally, or in the spleen (23).

\section{CONCLUSION}

Data suggested that inulin, specifically short chain, drives an anti-inflammatory response in PBMC in vitro. Although inulin is a potential source of new and selective compounds with pharmacological and immunological effects, its usefulness in therapeutics should be investigated. This work was an attempt to understand inulin effects in vitro in PBMC, opening perspectives for future prospects in this research field.

\section{CONFLICT OF INTEREST}

The authors confirm that this article content has no conflict of interest.

\section{ACKNOWLEDGEMENTS}

This work was supported by the Conselho Nacional de Desenvolvimento Científico e Tecnológico (CNPq) and Londrina State University Coordination for Postgraduation (PROPPG-UEL). The authors wish to express their gratitude to Fundação Araucária do Paraná, Secretaria da Ciência, Tecnologia e Ensino Superior (SETI) for supplying laboratory equipment. 


\section{REFERENCES}

1. Quigley EM. Prebiotics and probiotics: their role in the management of gastrointestinal disorders in adults. Nutr Clin Pract. 2012;27(2):195-200.

2. Thomas DW GF. Probiotics and prebiotics in pediatrics. Pediatrics. 2010;126(6):1217-31.

3. van Loo J, Coussement P, de Leenheer L, Hoebregs H, Smits G. On the presence of inulin and oligofructose as natural ingredients in the western diet. Crit Rev Food Sci Nutr. 1995;35(6):525-52.

4. Cooper PD, Carter M. The anti-melanoma activity of inulin in mice. Molecular immunology. 1986;23(8):903-8.

5. Korbelik M, Cooper PD. Potentiation of photodynamic therapy of cancer by complement: the effect of gamma-inulin. British Journal of Cancer. 2007;96(1):67-72.

6. Cooper PD, McComb C, Steele EJ. The adjuvanticity of Algammulin, a new vaccine adjuvant. Vaccine. 1991;9(6):408-15.

7. Silva DG, Cooper PD, Petrovsky N. Inulin-derived adjuvants efficiently promote both Th1 and Th2 immune responses. Immunology and cell biology. 2004;82(6):611-6.

8. Bodera P. Influence of prebiotics on the human immune system (GALT). Recent Pat Inflamm Allergy Drug Discov. 2008;2(2):149-53.

9. Vos AP, Haarman M, Buco A, Govers M, Knol J, Garssen J, et al. A specific prebiotic oligosaccharide mixture stimulates delayed-type hypersensitivity in a murine influenza vaccination model. Int Immunopharmacol. 2006;6(8):1277-86.

10. Sakaguchi S, Yamaguchi T, Nomura T, Ono M. Regulatory T cells and immune tolerance. Cell. 2008;133(5):775-87.

11. Toker A, Huehn J. To be or not to be a Treg cell: lineage decisions controlled by epigenetic mechanisms. Sci Signal. 2011;4(158):pe4.

12. Vignali D. How many mechanisms do regulatory $\mathrm{T}$ cells need? European Journal of Immunology. 2008;38(4):908-11.

13. Campbell DJ, Ziegler SF. FOXP3 modifies the phenotypic and functional properties of regulatory T cells. Nature reviews Immunology. 2007;7(4):305-10.

14. Sahin M, Sahin E, Koksoy S. Regulatory T cells in cancer: an overview and perspectives on cyclooxygenase-2 and Foxp3 DNA methylation. Hum Immunol. 2013;74(9):1061-8.

15. Chen W, Konkel JE. The development of thymic Foxp3 regulatory T cells: TGF-beta matters. European Journal of Immunology. 2015.

16. Chen W, Jin W, Hardegen N, Lei KJ, Li L, Marinos N, et al. Conversion of peripheral CD4+CD25- naive $\mathrm{T}$ cells to CD4+CD25+ regulatory $\mathrm{T}$ cells by TGF-beta induction of transcription factor Foxp3. The Journal of experimental medicine. 2003;198(12):1875-86.

17. Chen CJ, Yang HI, Su J, Jen CL, You SL, Lu SN, et al. Risk of hepatocellular carcinoma across a biological gradient of serum hepatitis B virus DNA level. Jama. 2006;295(1):6573.

18. Murai M, Turovskaya O, Kim G, Madan R, Karp CL, Cheroutre H, et al. Interleukin 10 acts on regulatory $\mathrm{T}$ cells to maintain expression of the transcription factor Foxp3 and suppressive function in mice with colitis. Nature immunology. 2009;10(11):1178-84.

19. Livak KJ, Schmittgen TD. Analysis of relative gene expression data using real-time quantitative PCR and the 2(-Delta Delta C(T)) Method. Methods. 2001;25(4):402-8.

20. Kim HS, Hong JT, Kim Y, Han SB. Stimulatory Effect of beta-glucans on Immune Cells. Immune network. 2011;11(4):191-5.

21. Nicotera P, Leist M, Ferrando-May E. Apoptosis and necrosis: different execution of the same death. Biochem Soc Symp. 1999;66:69-73.

22. Coussement PA. Inulin and oligofructose: safe intakes and legal status. The Journal of nutrition. 1999;129(7 Suppl):1412S-7S.

23. Vogt L, Meyer D, Pullens G, Faas M, Smelt M, Venema K, et al. Immunological properties of inulin-type fructans. Crit Rev Food Sci Nutr. 2015;55(3):414-36. 
24. Vogt L, Ramasamy U, Meyer D, Pullens G, Venema K, Faas MM, et al. Immune modulation by different types of beta2-->1-fructans is toll-like receptor dependent. PloS one. 2013;8(7):e68367.

25. Capitan-Canadas F, Ortega-Gonzalez M, Guadix E, Zarzuelo A, Suarez MD, de Medina FS, et al. Prebiotic oligosaccharides directly modulate proinflammatory cytokine production in monocytes via activation of TLR4. Mol Nutr Food Res. 2014;58(5):1098110.

26. Unutmaz D, Pulendran B. The gut feeling of Treg cells: IL-10 is the silver lining during colitis. Nature immunology. 2009;10(11):1141-3.

27. Kubo M, Motomura Y. Transcriptional regulation of the anti-inflammatory cytokine IL10 in acquired immune cells. Frontiers in immunology. 2012;3:275.

28. Kerekes K, Cooper PD, Prechl J, Jozsi M, Bajtay Z, Erdei A. Adjuvant effect of gammainulin is mediated by $\mathrm{C} 3$ fragments deposited on antigen-presenting cells. Journal of Leukocyte Biology. 2001;69(1):69-74.

29. Torok K, Dezso B, Bencsik A, Uzonyi B, Erdei A. Complement receptor type 1 (CR1/CD35) expressed on activated human CD4+ $\mathrm{T}$ cells contributes to generation of regulatory T cells. Immunology Lletters. 2015;164(2):117-24.

30. Bermudez-Brito M, Sahasrabudhe NM, Rosch C, Schols HA, Faas MM, de Vos P. The impact of dietary fibers on dendritic cell responses in vitro is dependent on the differential effects of the fibers on intestinal epithelial cells. Mol Nutr Food Res. 2015.

Received: July 06, 2016; Accepted: October 17, 2016 